\title{
PERDAS DE SOLO E DE ÁGUA E INFILTRAÇÃO DE ÁGUA EM LATOSSOLO VERMELHO SOB SISTEMAS DE MANEJO ${ }^{(1)}$
}

\author{
Elói Panachuki ${ }^{(2)}$, Ildegardis Bertol ${ }^{(3)}$, Teodorico Alves Sobrinho(4), \\ Paulo Tarso Sanches de Oliveira ${ }^{(5)} \&$ Dulce Buchala Bicca \\ Rodrigues $^{(6)}$
}

\begin{abstract}
RESUMO
Os sistemas de manejo do solo alteram o microrrelevo e a cobertura por resíduos vegetais, influenciando a perda de solo e de água. Assim, os objetivos deste estudo foram avaliar as perdas de solo e de água e estimar a taxa de infiltração estável de água no solo (TIE) em diferentes sistemas de manejo, sob chuva simulada. As avaliações de campo foram conduzidas sobre resíduos vegetais, após a colheita da cultura da soja (Glycine max L. Merril). Estudaram-se três sistemas de manejo do solo: semeadura direta, preparo com grade aradora e com escarificador associados a três níveis de cobertura do solo com resíduo vegetal: 0,$0 ; 2,0 ;$ e 4,0 $\mathrm{Mg} \mathrm{ha}^{-1}$. Para caracterizar a área experimental foram feitas análises de densidade do solo, macroporosidade, estabilidade de agregados, umidade inicial do solo, percentual de cobertura e rugosidade superficial do solo. Por meio do uso do simulador de chuvas portátil, as parcelas receberam aplicação de precipitações de $60 \mathrm{~mm} \mathrm{~h}^{-1}$. Os tratamentos foram dispostos segundo o delineamento inteiramente casualizado, arranjados em esquema fatorial $3 \times 3$, com três repetições. As perdas de solo variaram de 1,40 a $116,30 \times 10^{-3} \mathrm{Mg} \mathrm{ha}^{-1} \mathrm{~h}^{-1}$, enquanto as de água, de 1,60 a $106,94 \mathrm{~m}^{3} \mathrm{ha}^{-1} \mathrm{~h}^{-1}$. Os valores da TIE apresentaram variação entre $23 \mathrm{e} 52 \mathrm{~mm} \mathrm{~h}^{-1}$. Os tratamentos sob semeadura direta sem cobertura do solo e sob preparo com grade aradora apresentaram maiores perdas de solo e de água e valores mais baixos de TIE.
\end{abstract}

Termos de indexação: erosão hídrica, semeadura direta, preparo do solo, escoamento superficial, simulador de chuva.

(1) Parte da Tese de Doutorado do primeiro autor. Recebido para publicação em 17 de agosto de 2010 e aprovado em 12 de julho de 2011.

(2) Professor da Universidade Estadual de Mato Grosso do Sul - UEMS. Cx. Postal 25, CEP 79200-000 Aquidauana (MS). E-mail: eloip@uems.br

(3) Professor do Departamento de Solos do CAV/UDESC, CEP 88520-000 Lages (SC). Bolsista do CNPq. E-mail: a2ib@cav.udesc.br

(4) Professor Associado II da Universidade Federal de Mato Grosso do Sul - CCET/UFMS. Cx. Postal 549, CEP 79070-900 Campo Grande (MS). Bolsista do CNPq. E-mail: talves@ufms.br

(5) Doutorando em Engenharia Hidráulica e Saneamento na Universidade de São Paulo - USP. Cx. Postal 359, CEP 13560-970 São Carlos (SP). E-mail: paulot@sc.usp.br

(6) Doutoranda em Hidráulica e Saneamento na Universidade de São Paulo - USP. Cx. Postal 359, CEP 13560-970 São Carlos (SP). E-mail: dulce@sc.usp.br 


\title{
SUMMARY: SOIL AND WATER LOSS AND WATER INFILTRATION IN RED LATOSOL UNDER DIFFERENT MANAGEMENT SYSTEMS
}

\begin{abstract}
The soil management systems change the microrelief and the crop residue cover, influencing the soil and water losses. In this study evaluated the soil and water losses and estimated the water final infiltration rate in different soil managements models under simulated rainfall. Crop residues were evaluated in the field after harvest of soybean (Glycine max L. Merrill). Three soil managements systems were studied: no-tillage, disk harrow and chisel plow associated with three levels of dry soybean residue: 0 ; 2; and $4 \mathrm{Mg} \mathrm{ha} \mathrm{H}^{-1}$. In the experimental units, the soil bulk density, macroporosity, aggregate stability, initial moisture content, cover percentage and surface roughness were determined. Artificial rain was applied to each plot at an intensity of $60 \mathrm{~mm} \mathrm{~h}^{-1}$ by a portable rainfall simulator. The treatments were arranged in a completely randomized, factorial $3 x 3$ design with three replications. Soil loss ranged from 1.40 to $116.30 \times 10^{-3} \mathrm{Mg} \mathrm{ha}^{-1} \mathrm{~h}^{-1}$, while water loss ranged from 1.60 to $106.94 \mathrm{~m}^{3} \mathrm{ha}^{-1} \mathrm{~h}^{-1}$. The water final infiltration rate ranged from 23 to $52 \mathrm{~mm} \mathrm{~h}^{-1}$. Soil and water losses were highest and the final infiltration rate lowest in the treatments under no-tillage without soil cover and tilled with disk harrow.
\end{abstract}

Index-terms: water erosion, no-tillage, soil tillage, runoff, rainfall simulator.

\section{INTRODUÇÃO}

As operações de preparo do solo influenciam fortemente a erosão hídrica das áreas cultivadas, alterando o microrrelevo e a cobertura por resíduos vegetais e promovendo a exposição da superfície do solo à ação da chuva e da enxurrada. Segundo Albuquerque et al. (2002), à medida que o manejo do solo elimina a cobertura vegetal, a superfície fica mais exposta à ação do impacto das gotas de chuva e da enxurrada. Dessa forma, tanto o impacto das gotas de chuva quanto a ação cisalhante da enxurrada modificam as condições físicas da superfície do solo, como a rugosidade e a porosidade, e, consequentemente, a taxa de infiltração de água.

Conforme Bertol et al. (2001), os diferentes tipos de manejo e de cultivo do solo alteram as propriedades físicas e podem manifestar-se de várias maneiras, influenciando no crescimento e desenvolvimento das plantas. Assim, o solo cultivado tende, com o tempo, a ter a estrutura original alterada pelo fracionamento dos agregados em unidades menores, com consequente redução no volume de macroporos e aumentos no volume de microporos e na densidade do solo. Em decorrência disso, observou-se diminuição na taxa de infiltração de água no solo, com consequente aumento das taxas de escoamento superficial.

De maneira isolada, a presença da cobertura do solo por resíduos vegetais é o fator mais importante na dissipação da energia de impacto das gotas da chuva na superfície do solo, visto que ela pode evitar a desagregação de suas partículas. Além disso, resíduos vegetais em contato direto com a superfície do solo são eficazes na redução da carga de sedimentos no escoamento superficial ou enxurrada (Bertol et al., 2007). Desse modo, sistemas de manejo conservacionistas que promovam pequena ou nenhuma movimentação mecânica do solo, manutenção de maior parte dos resíduos culturais sobre a superfície e elevação da rugosidade superficial são mais eficazes do que os não conservacionistas no controle das perdas de solo e água por erosão hídrica (Cogo et al., 1984; Beutler et al., 2003). Nesse sentido, diversos estudos têm sido realizados com o intuito de avaliar como as diferentes formas de manejo têm influenciado no processo de perda de solo e de água (Cassol \& Lima, 2003; Mello et al., 2003; Volk et al., 2004; Carvalho et al., 2009).

Silva \& Kato (1998) obtiveram valores de taxa de infiltração estável média de $61,3 \mathrm{~mm} \mathrm{~h}^{-1} \mathrm{em}$ solo desprovido de cobertura vegetal e 76,3 $\mathrm{mm} \mathrm{h}^{-1} \mathrm{em}$ solo com cobertura morta. Isso evidencia a importante função desempenhada pela cobertura vegetal no favorecimento da elevação da taxa de infiltração de água no solo. Albuquerque et al. (2002) verificaram que parcelas com cobertura morta reduziram as perdas de solo e água em 99 e 74 \%, respectivamente, em relação às parcelas sem cobertura do solo.

Beutler et al. (2003), com relação ao preparo do solo, concluíram que a semeadura direta, tanto envolvendo rotação de culturas no inverno e verão quanto envolvendo rotação de preparos, é mais eficaz no controle das perdas de solo e de água do que o preparo convencional com grade aradora, cultivo mínimo com escarificador, rotação de ferramentas de preparos e semeadura direta. Mello et al. (2003) verificaram que o cultivo mínimo reduziu as perdas de solo em $85 \%$ e as de água em $34 \%$ em relação ao preparo de solo com arado e grade, durante o cultivo da soja.

Desse modo, este trabalho teve por objetivos avaliar as perdas de solo e de água e estimar a taxa de infiltração estável de água no solo, sob chuva simulada, em diferentes sistemas de manejo do solo, após o cultivo da soja (Glycine max L. Merrill). 


\section{MATERIAL E MÉTODOS}

O experimento foi desenvolvido em área experimental da Embrapa Agropecuária Oeste cultivada com soja (Glycine max L. Merrill), em Dourados, MS. O solo foi classificado como Latossolo Vermelho aluminoférrico típico, com granulometria de $200 \mathrm{~g} \mathrm{~kg}^{-1}$ de areia, $94 \mathrm{~g} \mathrm{~kg}^{-1}$ de silte e $706 \mathrm{~g} \mathrm{~kg}^{-1}$ de argila. O relevo da região é plano a suaveondulado e a declividade média da área experimental, de aproximadamente $0,03 \mathrm{~m} \mathrm{~m}^{-1}$.

As avaliações de perdas de solo, de água e de infiltração foram efetuadas em três tipos de manejo do solo. Utilizou-se o simulador de chuvas desenvolvido por Alves Sobrinho et al. (2002, 2008), calibrado para aplicar chuva de intensidade constante igual a $60 \mathrm{~mm} \mathrm{~h}^{-1}$. Os testes, ou ensaios de campo com o simulador, foram realizados após a colheita da soja.

Estudaram-se três sistemas de manejo do solo: semeadura direta (SD), preparo com grade aradora (PC) e preparo com escarificador (CM) associados a três níveis de cobertura do solo: 0,$0 ; 2,0 ; \mathrm{e} 4,0 \mathrm{Mg} \mathrm{ha}^{-1}$. No preparo com grade aradora foi realizada uma operação com grade de 20 discos de $0,58 \mathrm{~m}$ de diâmetro seguida de duas operações com grade niveladora de 32 discos de $0,43 \mathrm{~m}$ de diâmetro. O preparo com escarificador consistiu de uma operação com escarificador de hastes seguida de uma gradagem com grade niveladora. O escarificador usado no preparo do solo possuía sete hastes distanciadas de $0,25 \mathrm{~m}$, que atingiram a profundidade média de $0,20 \mathrm{~m}$. As operações de preparo do solo foram realizadas sobre os resíduos vegetais da cultura da soja, com exceção dos tratamentos caracterizados pela ausência dos resíduos, em que as operações foram executadas sobre o solo livre de qualquer tipo de cobertura vegetal.

Os tratamentos foram caracterizados da seguinte maneira: tratamento 1 - semeadura direta sem resíduo (SD-0); tratamento 2 - semeadura direta com $2,0 \mathrm{Mg} \mathrm{ha}^{-1}$ de resíduo (SD-2); tratamento 3 semeadura direta com 4,0 Mg ha-1 de resíduo (SD-4); tratamento 4 - preparo com grade aradora sem resíduo (PC-0); tratamento 5 - preparo com grade aradora com $2,0 \mathrm{Mg} \mathrm{ha}^{-1}$ de resíduo (PC-2); tratamento 6 - preparo com grade aradora com 4,0 Mg ha ${ }^{-1}$ de resíduo (PC4); tratamento 7 - preparo com escarificador sem resíduo (CM-0); tratamento 8 - preparo com escarificador com 2,0 $\mathrm{Mg} \mathrm{ha}^{-1}$ de resíduo (CM-2); e tratamento 9 - preparo com escarificador com 4,0 Mg ha-1 de resíduo (CM-4).

A área da parcela experimental $\left(\mathrm{de} 0,7 \mathrm{~m}^{2}\right)$ que recebia a chuva simulada era contornada por dispositivo de formato retangular, construído em chapas de aço galvanizadas $(0,7 \mathrm{~m}$ de largura, $1,0 \mathrm{~m}$ de comprimento e $0,2 \mathrm{~m}$ de altura). Tal dispositivo, instalado no campo com o comprimento maior a favor do declive, era cravado na parte central da área de ação do simulador de chuvas até a profundidade de $0,12 \mathrm{~m}$.
Com o objetivo de estabelecer adequada caracterização dos principais atributos físicos do solo da área experimental, foram feitas as seguintes análises: (a) densidade e macroporosidade - foram coletadas amostras indeformadas de solo representativas da profundidade de $0-0,05 \mathrm{~m}$ (Embrapa, 1997); e (b) estabilidade de agregados via úmida - as amostras para essa determinação consistiram de blocos de solo com estrutura natural, que, após secos ao ar, foram passados em peneiras de 9,52 e $4,76 \mathrm{~mm}$, sendo empregados nas análises posteriores aqueles agregados retidos na peneira de 4,76 mm. A análise de estabilidade de agregados pelo peneiramento via úmida foi realizada pelo peneiramento durante $10 \mathrm{~min}$, em jogo de peneiras com malhas de 2,$0 ; 1,0 ; 0,5 ; 0,25$; e $0,105 \mathrm{~mm}$, dentro de recipiente imerso em água (Embrapa, 1997). Adotou-se como índice de estabilidade de agregados o diâmetro médio geométrico (DMG), com cálculos feitos seguindo o método de Kemper \& Rosenau (1986). Além disso, estimou-se a percentagem de cobertura do solo causada pelos resíduos vegetais mediante o uso do método fotográfico com projeção de grade formada por 50 interseções sobre a fotografia, fazendo-se a contagem das interseções dos pontos dessa grade com a presença ou não de cobertura vegetal nesses pontos (Panachuki, 2008).

Após a realização dos testes de infiltração de água no solo, foi estimada a rugosidade da superfície do solo. Os valores das alturas do microrrelevo do solo foram obtidos com o uso de rugosímetro de varetas acoplado à máquina fotográfica digital, conforme descrito em Zoldan Júnior et al. (2008).

\section{Perdas de solo e de água}

Em cada tratamento foram aplicadas sete chuvas com duração de 60 min, separadas por um período de tempo de uma semana. A magnitude média da energia cinética causada por cada chuva foi de $1,45 \mathrm{~kJ} \mathrm{~m}^{-2}$, estimada utilizando-se o programa computacional EnerChuva (Alves Sobrinho et al., 2001). As unidades experimentais permaneceram cobertas no período entre as chuvas simuladas para evitar o efeito de chuvas naturais.

As avaliações de perdas de solo e de água tiveram início com a coleta de amostras do volume escoado em cada parcela, em recipientes de $1 \mathrm{~L}$, em intervalos de 5 min entre cada amostra. A coleta da primeira amostra era realizada quando verificava-se o início do escoamento de água na calha coletora e finalizado após $1 \mathrm{~h}$ de chuva simulada. Considerou-se que, decorridos os 5 min e o recipiente não estivesse completamente cheio, a coleta era interrompida, o frasco vedado e imediatamente era iniciada a coleta da amostra seguinte. Ao contrário, se durante o intervalo de 5 min o recipiente ficasse completamente cheio, a coleta era interrompida e o tempo, registrado. Nesse caso, a amostragem seguinte era feita após os 5 min do início da coleta anterior. 
O intervalo de tempo compreendido entre o início da aplicação da chuva simulada e o início da coleta foi identificado como tempo de início do escoamento superficial, registrado em cada parcela do experimento.

Ao final da avaliação de campo, as amostras eram encaminhadas ao laboratório para que fossem feitas as medições da massa de solo e do volume de água escoado. As amostras eram deixadas em repouso até que o material sólido em suspensão sofresse decantação. Após a decantação do material sólido, o volume de água era drenado e medido. As amostras de material sólido eram, então, colocadas em estufa na temperatura de $60{ }^{\circ} \mathrm{C}$, por período de tempo necessário à completa evaporação da água.

\section{Infiltração de água no solo}

Posteriormente à realização dos testes de chuva, com aplicação de $420 \mathrm{~mm}$ correspondentes a sete eventos de chuvas de $60 \mathrm{~mm}$ cada, em que foram avaliadas as perdas de solo e de água, fez-se, então, a aplicação de chuva, em evento único, de intensidade constante de $60 \mathrm{~mm} \mathrm{~h}^{-1}$, com duração suficiente para que fosse atingida a taxa de infiltração estável de água no solo (TIE).

Antes do início dos testes para avaliar a infiltração de água no solo, as parcelas receberam um prémolhamento com o objetivo de oferecer condições de umidade uniforme a todas elas, constituindo-se um pré-requisito antes da aplicação da chuva artificial (Cogo et al., 1984). Para isso, o simulador foi calibrado para aplicar intensidade de chuva de $60 \mathrm{~mm} \mathrm{~h}^{-1}$, durante tempo suficiente para saturar o solo, sem que houvesse escoamento superficial. Depois de ter sido feito o pré-molhamento das parcelas, após um intervalo de tempo de $24 \mathrm{~h}$, foram coletadas amostras de solo para a avaliação da umidade (Embrapa, 1997), nas camadas de 0 a 0,$05 ; 0,05$ a 0,10 ; e 0,10 a $0,20 \mathrm{~m}$ e, em seguida, iniciados os testes de TIE.

A coleta da água escoada foi feita na calha coletora durante $1 \mathrm{~min}$, com intervalos de tempo entre as coletas de 1, 2, 3, 5, 10 e 15 min, com cinco repetições em cada intervalo, até que o volume escoado superficialmente se tornasse constante (Panachuki et al., 2006). Após as tomadas de dados em cada unidade experimental, era verificada a intensidade de precipitação aplicada durante o teste.

As curvas de infiltração foram ajustadas ao modelo de Horton (Horton, 1933) (Equação 1), conforme recomendações de Alves Sobrinho et al. (2003) e Panachuki et al. (2006), utilizando para tanto o software Graph (Johansen, 2009).

$$
f_{t}=f_{c}+\left(f_{0}-f_{c}\right) e^{-\mathrm{kt}}
$$

em que $f_{t}=$ taxa de infiltração no tempo t; $t=$ tempo transcorrido desde o início do processo de infiltração; $f_{0}=$ taxa de infiltração inicial (tempo $\mathrm{t}=0$ ); $f_{c}=$ taxa de infiltração alcançada quando a umidade do solo estava próxima da saturação; $\mathrm{e} k=$ taxa de decaimento constante da taxa de infiltração, específica para cada solo.

\section{Análises estatísticas}

Os resultados da combinação dos três tipos de manejo do solo, associados aos três níveis de resíduo vegetal, foram dispostos segundo um delineamento inteiramente casualizado e arranjados em esquema fatorial $3 \times 3$, com três repetições, totalizando 27 parcelas experimentais.

Para avaliar o efeito dos tratamentos e obter a estimativa da variância residual, foi feita a análise de variância dos dados obtidos com a posterior aplicação do teste de Tukey a $5 \%$, para comparar as médias.

\section{RESULTADOS E DISCUSSÃO}

\section{Perdas de solo e de água}

Os valores dos atributos necessários à caracterização física do solo nas unidades experimentais encontram-se no quadro 1. Na semeadura direta, após as operações de preparo do solo e aplicação das chuvas simuladas, a densidade foi superior à dos demais tipos de manejo do solo, proporcionando a este menor macroporosidade.

Os valores de DMG, no momento anterior ao preparo do solo, foram semelhantes entre todos os tratamentos, apresentando, entretanto, no momento posterior ao do preparo do solo e aplicação das chuvas simuladas tendência de ser superior na semeadura direta. Essa melhor estabilidade dos agregados nos tratamentos sob semeadura direta está relacionada à presença prolongada da matéria orgânica que atua como agente agregante do solo. De acordo com Tisdall \& Oades (1982), na ausência de operações de preparo do solo que causam o seu revolvimento, a combinação da menor taxa de decomposição da matéria orgânica com a ação das raízes, dos microrganismos e da fauna do solo favorecer o agrupamento dos microagregados, resultando na formação de macroagregados estáveis.

Os valores de perdas de solo e de água nos tratamentos submetidos aos diferentes tipos de manejo estão ilustrados no quadro 2 . Verifica-se, que no SD0 as perdas de solo e de água iniciaram na chuva 3 , aumentando significativamente na chuva 4 e permanecendo com valores elevados até o último teste. Isso se deve, possivelmente, ao baixo valor de rugosidade da superfície (Quadro 3) e selamento da superfície do solo (Panachuki, 2008) promovidos pelo impacto das gotas de chuva, que favoreceram o aumento do escoamento superficial. No tratamento SD-2, o escoamento superficial iniciou apenas na quinta chuva, promovendo perdas significativamente menores do que na condição sem cobertura do solo 
Quadro 1. Valores médios de densidade do solo (Ds), macroporosidade (Ma) e diâmetro médio geométrico de agregados do solo (DMG), antes das operações de preparo do solo e após a aplicação das chuvas simuladas, na profundidade de $0-0,05 \mathrm{~m}$

\begin{tabular}{|c|c|c|c|c|c|c|}
\hline \multirow{2}{*}{ Tratamento } & \multicolumn{3}{|c|}{ Antes do preparo do solo } & \multicolumn{3}{|c|}{ Após a aplicação das chuvas } \\
\hline & Ds & Ma & DMG & Ds & Ma & DMG \\
\hline & $\mathrm{Mg} \mathrm{m}^{-3}$ & $\mathrm{~m}^{3} \mathrm{~m}^{-3}$ & $\mathrm{~mm}$ & $\mathrm{Mg} \mathrm{m}^{-3}$ & $\mathrm{~m}^{3} \mathrm{~m}^{-3}$ & $\mathrm{~mm}$ \\
\hline SD-0 & $1,30 \mathrm{~b}$ & $0,17 \mathrm{~b}$ & $4,18 \mathrm{a}$ & $1,32 \mathrm{a}$ & $0,17 \mathrm{c}$ & $4,24 \mathrm{a}$ \\
\hline SD - 2 & $1,31 \mathrm{ab}$ & $0,16 \mathrm{~b}$ & $4,21 \mathrm{a}$ & $1,35 \mathrm{a}$ & $0,16 \mathrm{c}$ & $3,93 \mathrm{ab}$ \\
\hline SD - 4 & $1,44 \mathrm{a}$ & $0,11 \mathrm{c}$ & $4,40 \mathrm{a}$ & $1,29 \mathrm{ab}$ & $0,15 \mathrm{c}$ & $4,36 \mathrm{a}$ \\
\hline PC - 0 & $1,26 \mathrm{~b}$ & $0,18 \mathrm{ab}$ & $4,15 \mathrm{a}$ & $1,16 \mathrm{c}$ & $0,29 \mathrm{a}$ & $3,19 \mathrm{c}$ \\
\hline $\mathrm{PC}-2$ & $1,35 \mathrm{ab}$ & $0,15 \mathrm{~b}$ & $4,11 \mathrm{a}$ & $1,06 \mathrm{~d}$ & $0,24 \mathrm{ab}$ & $3,91 \mathrm{ab}$ \\
\hline $\mathrm{PC}-4$ & $1,32 \mathrm{ab}$ & $0,17 \mathrm{~b}$ & $4,08 \mathrm{a}$ & $1,05 \mathrm{~d}$ & $0,29 \mathrm{a}$ & $3,22 \mathrm{c}$ \\
\hline CM - 0 & $1,24 \mathrm{~b}$ & $0,18 \mathrm{~b}$ & $4,48 \mathrm{a}$ & $1,16 \mathrm{c}$ & $0,26 \mathrm{ab}$ & $3,62 \mathrm{abc}$ \\
\hline CM - 2 & $1,26 \mathrm{~b}$ & 0,23 a & $4,30 \mathrm{a}$ & $1,15 \mathrm{c}$ & $0,25 \mathrm{ab}$ & $3,46 \mathrm{bc}$ \\
\hline $\mathrm{CM}-4$ & $1,33 \mathrm{ab}$ & $0,17 \mathrm{~b}$ & $4,36 \mathrm{a}$ & $1,22 \mathrm{bc}$ & $0,23 \mathrm{~b}$ & $4,25 \mathrm{a}$ \\
\hline
\end{tabular}

SD: semeadura direta, PC: preparo com grade aradora e CM: preparo com escarificador. Médias seguidas da mesma letra minúscula na mesma coluna não diferem entre si pelo teste de Tukey a $5 \%$.

Quadro 2. Perdas de solo e de água em diferentes tipos de manejo do solo e momentos de determinação

\begin{tabular}{|c|c|c|c|c|c|c|c|c|}
\hline \multirow{2}{*}{$\begin{array}{l}\text { Preparo } \\
\text { do solo }\end{array}$} & \multirow{2}{*}{$\begin{array}{l}\text { Resíduo } \\
\text { vegetal }\end{array}$} & \multicolumn{7}{|c|}{ Momento da determinação } \\
\hline & & Chuva 1 & Chuva 2 & Chuva 3 & Chuva 4 & Chuva 5 & Chuva 6 & Chuva 7 \\
\hline & $\mathrm{Mg} \mathrm{ha}^{-1}$ & \multicolumn{7}{|c|}{ Perdas de solo, $10^{-3} \mathrm{Mg} \mathrm{ha}^{-1} \mathrm{~h}^{-1}$} \\
\hline $\mathrm{SD}$ & $\begin{array}{l}0,0 \\
2,0 \\
4,0\end{array}$ & $\begin{array}{l}0 \\
0 \\
0\end{array}$ & $\begin{array}{l}0 \\
0 \\
0\end{array}$ & $\begin{array}{l}11,90 \mathrm{~B} \\
0 \\
0\end{array}$ & $\begin{array}{c}105,10 \mathrm{Aa} \\
0 \\
0\end{array}$ & $\begin{array}{c}93,00 \mathrm{Aa} \\
1,60 \mathrm{Bb} \\
0\end{array}$ & $\begin{array}{c}125,00 \mathrm{Aa} \\
3,30 \mathrm{Bc} \\
0\end{array}$ & $\begin{array}{c}116,30 \mathrm{Aa} \\
9,80 \mathrm{Ab} \\
0\end{array}$ \\
\hline $\mathrm{PC}$ & $\begin{array}{l}0,0 \\
2,0 \\
4,0\end{array}$ & $\begin{array}{l}0 \\
0 \\
0\end{array}$ & $\begin{array}{l}0 \\
0 \\
0\end{array}$ & $\begin{array}{l}0 \\
0 \\
0\end{array}$ & $\begin{array}{r}8,60 \mathrm{Bb} \\
15,30 \mathrm{Bb} \\
2,50 \mathrm{Bb}\end{array}$ & $\begin{array}{l}16,80 \mathrm{Bb} \\
23,90 \mathrm{ABb} \\
22,50 \mathrm{Ab}\end{array}$ & $\begin{array}{l}22,50 \mathrm{Bbc} \\
16,40 \mathrm{Bbc} \\
36,30 \mathrm{Ab}\end{array}$ & $\begin{array}{l}48,80 \mathrm{Ab} \\
34,50 \mathrm{Ab} \\
27,40 \mathrm{Ab}\end{array}$ \\
\hline $\mathrm{CM}$ & $\begin{array}{l}0 \\
2,0 \\
4,0\end{array}$ & $\begin{array}{l}0 \\
0 \\
0\end{array}$ & $\begin{array}{l}0 \\
0 \\
0\end{array}$ & $\begin{array}{l}0 \\
0 \\
0\end{array}$ & $\begin{array}{l}1,40 \mathrm{Bb} \\
0 \\
0\end{array}$ & $\begin{array}{l}6,30 \mathrm{Bb} \\
0 \\
0\end{array}$ & $\begin{array}{l}18,70 \mathrm{Abc} \\
0 \\
0\end{array}$ & $\begin{array}{l}16,90 \mathrm{Ab} \\
0 \\
0\end{array}$ \\
\hline $\mathrm{SD}$ & $\begin{array}{l}0,0 \\
2,0 \\
4,0\end{array}$ & $\begin{array}{l}0 \\
0 \\
0\end{array}$ & $\begin{array}{l}0 \\
0 \\
0\end{array}$ & $\begin{array}{l}\text { P } \\
21,13 \mathrm{~B} \\
0 \\
0\end{array}$ & $\begin{array}{l}\text { as de água, } \\
85,61 \mathrm{Aa} \\
0 \\
0\end{array}$ & $\begin{array}{l}\mathrm{a}^{-1} \mathrm{~h}^{-1} \\
75,2 \mathrm{Aa} \\
5,34 \mathrm{Bb} \\
0\end{array}$ & $\begin{array}{l}90,53 \mathrm{Aa} \\
13,48 \mathrm{ABb} \\
0\end{array}$ & $\begin{array}{c}106,94 \mathrm{Aa} \\
17,59 \mathrm{Ac} \\
0\end{array}$ \\
\hline $\mathrm{PC}$ & $\begin{array}{l}0,0 \\
2,0 \\
4,0\end{array}$ & $\begin{array}{l}0 \\
0 \\
0\end{array}$ & $\begin{array}{l}0 \\
0 \\
0\end{array}$ & $\begin{array}{l}0 \\
0 \\
0\end{array}$ & $\begin{array}{r}5,40 \mathrm{Cb} \\
7,50 \mathrm{Bb} \\
12,30 \mathrm{Bb}\end{array}$ & $\begin{array}{l}16,50 \mathrm{BCb} \\
13,70 \mathrm{ABb} \\
18,1 \mathrm{Bb}\end{array}$ & $\begin{array}{l}18,90 \mathrm{Bb} \\
16,50 \mathrm{ABb} \\
21,7 \mathrm{Bb}\end{array}$ & $\begin{array}{l}33,30 \mathrm{Ab} \\
25,20 \mathrm{Abc} \\
37,5 \mathrm{Ab}\end{array}$ \\
\hline $\mathrm{CM}$ & $\begin{array}{l}0 \\
2,0 \\
4,0\end{array}$ & $\begin{array}{l}0 \\
0 \\
0\end{array}$ & $\begin{array}{l}0 \\
0 \\
0\end{array}$ & $\begin{array}{l}0 \\
0 \\
0\end{array}$ & $\begin{array}{l}1,60 \mathrm{Cb} \\
0 \\
0\end{array}$ & $\begin{array}{l}6,30 \mathrm{BCb} \\
0 \\
0\end{array}$ & $\begin{array}{l}12,84 \mathrm{Ab} \\
0 \\
0\end{array}$ & $\begin{array}{l}10,68 \mathrm{ABc} \\
0 \\
0\end{array}$ \\
\hline
\end{tabular}

SD: semeadura direta; PC: preparo com grade aradora; e CM: preparo com escarificador. Médias seguidas da mesma letra maiúscula, na mesma linha, e minúscula, na mesma coluna, não diferem entre si pelo teste de Tukey a $5 \%$.

(SD-0), enquanto na condição com nível máximo de cobertura do solo (SD-4) não foram verificadas perdas de solo e de água. Esse efeito causado pela cobertura vegetal na redução da erosão hídrica, em sistemas conservacionistas, está relacionado à sua capacidade de amortecer o impacto da energia cinética das gotas de chuva e de amenizar o escoamento superficial, o que está de acordo com os dados obtidos por Mello et al. (2003).
No preparo com grade aradora ocorreram perdas de solo e de água, em todos os tratamentos, a partir da quarta chuva. Nesse tipo de preparo do solo, podese considerar que as diferentes quantidades de resíduos vegetais adicionadas à superfície do solo e posteriormente incorporados não foram eficientes em diminuir as perdas de solo e de água por erosão. Isso deve-se, basicamente, à incorporação dos resíduos vegetais causada pelo revolvimento, o que fez que os 
Quadro 3. Valores médios de cobertura do solo, rugosidade superficial do solo, umidade do solo, intensidade de precipitação aplicada, energia cinética da chuva simulada, relação percentual entre a energia cinética da chuva simulada e a natural (Ecs/Ecn), tempo de início de escoamento superficial, tempo de aplicação da chuva simulada e taxa de infiltração

\begin{tabular}{|c|c|c|c|c|c|c|c|c|c|}
\hline & \multicolumn{3}{|c|}{ Semeadura direta } & \multicolumn{3}{|c|}{ Preparo Convencional } & \multicolumn{3}{|c|}{ Cultivo mínimo } \\
\hline & \multicolumn{9}{|c|}{ Massa de resíduo vegetal sobre a superfície do solo $\left(\mathrm{Mg} \mathrm{ha}^{-1}\right)$} \\
\hline & 0 & 2,0 & 4,0 & 0 & 2,0 & 4,0 & 0 & 2,0 & 4,0 \\
\hline & \multicolumn{9}{|c|}{ Cobertura do solo (\%) } \\
\hline Profundidade & 0,0 & 65,0 & 77,0 & 0,0 & 11,0 & 16,0 & 0,0 & 14,0 & 23,0 \\
\hline $\mathrm{cm}$ & \multicolumn{9}{|c|}{ Umidade inicial do solo (\% à base massa) } \\
\hline $0-5$ & $28,5 \mathrm{Aa}$ & $28,2 \mathrm{Aa}$ & $30,3 \mathrm{Aa}$ & $27,7 \mathrm{Aa}$ & $26,4 \mathrm{Aa}$ & $26,3 \mathrm{Aa}$ & $27,3 \mathrm{Aa}$ & $26,2 \mathrm{Aa}$ & $27,3 \mathrm{Aa}$ \\
\hline $5-10$ & $27,7 \mathrm{Aa}$ & $27,2 \mathrm{Aa}$ & $29,7 \mathrm{Aa}$ & $27,6 \mathrm{Aa}$ & $25,9 \mathrm{Aa}$ & $26,2 \mathrm{Aa}$ & $28,2 \mathrm{Aa}$ & $27,2 \mathrm{Aa}$ & $27,9 \mathrm{Aa}$ \\
\hline \multirow[t]{7}{*}{$10-20$} & $27,0 \mathrm{Aa}$ & $26,8 \mathrm{Aa}$ & $28,1 \mathrm{Aa}$ & $26,3 \mathrm{Aa}$ & $25,2 \mathrm{Aa}$ & $25,9 \mathrm{Aa}$ & $27,1 \mathrm{Aa}$ & $27,2 \mathrm{Aa}$ & $26,6 \mathrm{Aa}$ \\
\hline & \multicolumn{9}{|c|}{ Rugosidade da superfície do solo ao acaso (mm) } \\
\hline & $0,93 \mathrm{c}$ & $2,32 \mathrm{bc}$ & $3,28 \mathrm{~b}$ & $3,52 \mathrm{~b}$ & $3,59 \mathrm{~b}$ & $2,95 \mathrm{bc}$ & 7,86 a & 9,58 a & 9,14 a \\
\hline & \multicolumn{9}{|c|}{ Intensidade da chuva simulada aplicada $\left(\mathrm{mm} \mathrm{h}^{-1}\right)$} \\
\hline & 61 & 59 & 61 & 62 & 60 & 61 & 60 & 61 & 59 \\
\hline & \multicolumn{9}{|c|}{ Energia cinética da chuva simulada $\left(\mathrm{kJ} \mathrm{m}^{-2}\right)$} \\
\hline & 3,86 & 4,12 & 4,79 & 4,06 & 4,09 & 4,29 & 4,38 & 4,39 & 4,40 \\
\hline \multirow[t]{6}{*}{$\operatorname{Ecs} / \operatorname{Ecn}(\%)$} & 91,67 & 91,76 & 91,45 & 91,50 & 91,70 & 91,41 & 91,49 & 91,44 & 91,65 \\
\hline & \multicolumn{9}{|c|}{ Tempo de início do escoamento superficial (min) } \\
\hline & 04 & 16 & 38 & 05 & 12 & 16 & 24 & 21 & 28 \\
\hline & \multicolumn{9}{|c|}{ Duração da chuva simulada (min) } \\
\hline & 161 & 173 & 195 & 162 & 169 & 173 & 181 & 178 & 185 \\
\hline & \multicolumn{9}{|c|}{ Taxa de infiltração $\left(\mathrm{mm} \mathrm{h}^{-1}\right)$} \\
\hline Inicial & $59,4 \mathrm{Aa}$ & $58,8 \mathrm{Aa}$ & $59,3 \mathrm{Aa}$ & $60,7 \mathrm{Aa}$ & $59,2 \mathrm{Aa}$ & $58,9 \mathrm{Aa}$ & $59,3 \mathrm{Aa}$ & $59,2 \mathrm{Aa}$ & $58,2 \mathrm{Aa}$ \\
\hline Estável & $24,4 \mathrm{Bb}$ & $48,8 \mathrm{Aa}$ & $52,3 \mathrm{Aa}$ & $29,6 \mathrm{Bb}$ & $26,4 \mathrm{Bb}$ & $23,5 \mathrm{Bb}$ & $45,7 \mathrm{Aa}$ & $51,2 \mathrm{Aa}$ & $48,2 \mathrm{~A} \mathrm{a}$ \\
\hline
\end{tabular}

Médias seguidas da mesma letra maiúscula, na mesma linha, e minúscula, na mesma coluna, não diferem entre si pelo teste de Tukey a $5 \%$.

percentuais de cobertura (Quadro 3) fossem baixos e semelhantes entre os três níveis de resíduos. Os valores de perdas de solo e de água, nesse tipo de preparo, foram menores do que aqueles observados no tratamento SD-0. Nessas condições, isso é explicado pelas operações de preparo que favoreceram a infiltração de água, principalmente nos primeiros testes, diminuindo, assim, o escoamento superficial (Quadro 3). Entretanto, observa-se que ocorreu, nos tratamentos PC, aumento gradativo nas perdas de solo e de água à medida que se aplicavam os testes de chuva, em decorrência, possivelmente, do efeito da energia cinética da chuva em promover o selamento superficial e diminuir a rugosidade superficial do solo.

De maneira geral, pode-se considerar que os tratamentos caracterizados como semeadura direta e preparo com escarificador com a presença dos resíduos vegetais na superfície do solo tenderam a ser mais eficientes no controle da erosão, pois, na maioria dos testes de simulação de chuva nesses tratamentos, não houve escoamento superficial.

Analisando apenas a sétima chuva (Quadro 2), as perdas de água em relação ao total precipitado situaram-se, em média, próximas a 18, 6 e $2 \%$, na semeadura direta sem cobertura do solo (SD-0), no preparo com grade aradora e no preparo com escarificador sem cobertura do solo (CM-0), respectivamente. Essas perdas foram semelhantes às obtidas por Cogo et al. (2003) para o preparo convencional e o cultivo mínimo, sendo, entretanto, inferiores às encontradas por Bertol et al. (2008) sob cultivo mínimo em Nitossolo Háplico, em que tais perdas variaram de 4 a $46 \%$ do volume de chuva aplicado.

No preparo com escarificador foram verificadas perdas de solo e de água somente na ausência de resíduo vegetal sobre a superfície do solo, com valores semelhantes aos observados nos tratamentos sob semeadura direta com cobertura do solo. Isso indica que, nesse sistema de preparo, o efeito da ação das hastes do escarificador em romper as camadas compactadas e aumentar a rugosidade superficial pode ser tão efetivo na redução do processo erosivo quanto os benefícios da cobertura vegetal morta atuando sobre a superfície do solo, conforme argumentado por Cogo (1981).

\section{Infiltração de água no solo}

Com relação à intensidade das chuvas aplicadas, verificou-se que os valores foram ligeiramente 
diferentes do planejado $\left(60 \mathrm{~mm} \mathrm{~h}^{-1}\right)$, em função das características operacionais e da montagem do equipamento no campo (Quadro 3). Entretanto, devese considerar que essas variações não interferiram na avaliação da taxa de infiltração de água no solo, representando um afastamento de no máximo 3,33\% da intensidade planejada (Quadro 3), e não houve efeito na quantidade de energia das chuvas aplicadas.

Entre as grandezas físicas utilizadas pelo programa EnerChuva para o cálculo da energia cinética, verificou-se que a lâmina média de água aplicada sobre cada parcela experimental foi a única que sofreu variações entre uma chuva e outra, causando, com isso, as diferenças verificadas no valor da energia cinética entre os tratamentos. As variações nos valores da lâmina média de água necessária para que a taxa de infiltração de água no solo atingisse a estabilidade ocorreram, basicamente, em função das diferentes durações das chuvas.

As relações entre os valores de energia cinética das chuvas simuladas e das chuvas naturais foram iguais a $91 \%$, em todos os tratamentos avaliados, permitindo considerar que as características das chuvas aplicadas foram semelhantes às da chuva natural, nessa intensidade de precipitação.

As taxas de infiltração foram de magnitude próxima ao valor da intensidade de precipitação aplicada, no início do escoamento superficial. Entretanto, tenderam a diminuir com o aumento da duração da chuva, até atingir valor constante. Os valores observados da TIE foram, no caso da semeadura direta com cobertura do solo, semelhantes aos observados por Panachuki et al. (2006), que obtiveram a TIE de 49,24 $\mathrm{mm} \mathrm{h}^{-1}$. Entretanto, os resultados divergiram dos obtidos por Alves Sobrinho et al. (2003), que obtiveram valores variando de 22 a $45 \mathrm{~mm} \mathrm{~h}^{-1}$ na semeadura direta e de $14,5 \mathrm{~mm} \mathrm{~h}^{-1}$ no tratamento preparado com grade aradora. Tais resultados são, contudo, justificáveis e aceitáveis. Evidenciam a variabilidades dos atributos dos solos e a necessidade de pesquisas aplicadas de forma a obter limites referenciais de valores aceitáveis para aplicação nos diversos campos de estudo.

Verificou-se bom ajuste do modelo de Horton aos dados de infiltração, sendo obtidos valores do coeficiente de determinação superiores a 90 \% (Figura 1).

No manejo com semeadura direta, a condição sem resíduo sobre a superfície do solo (SD-0) propiciou o menor valor da taxa de infiltração estável (TIE), equivalendo a $41 \%$ da taxa de infiltração inicial e $50 \%$ daquela obtida no nível intermediário de resíduo vegetal (SD-2), conforme pode ser observado no quadro 3. No tratamento SD-2, o valor da TIE foi alto, correspondendo a $83 \%$ da taxa de infiltração inicial, o que mostrou que o efeito dos resíduos vegetais sobre a superfície do solo, mesmo que com a metade da quantidade máxima de resteva produzida por
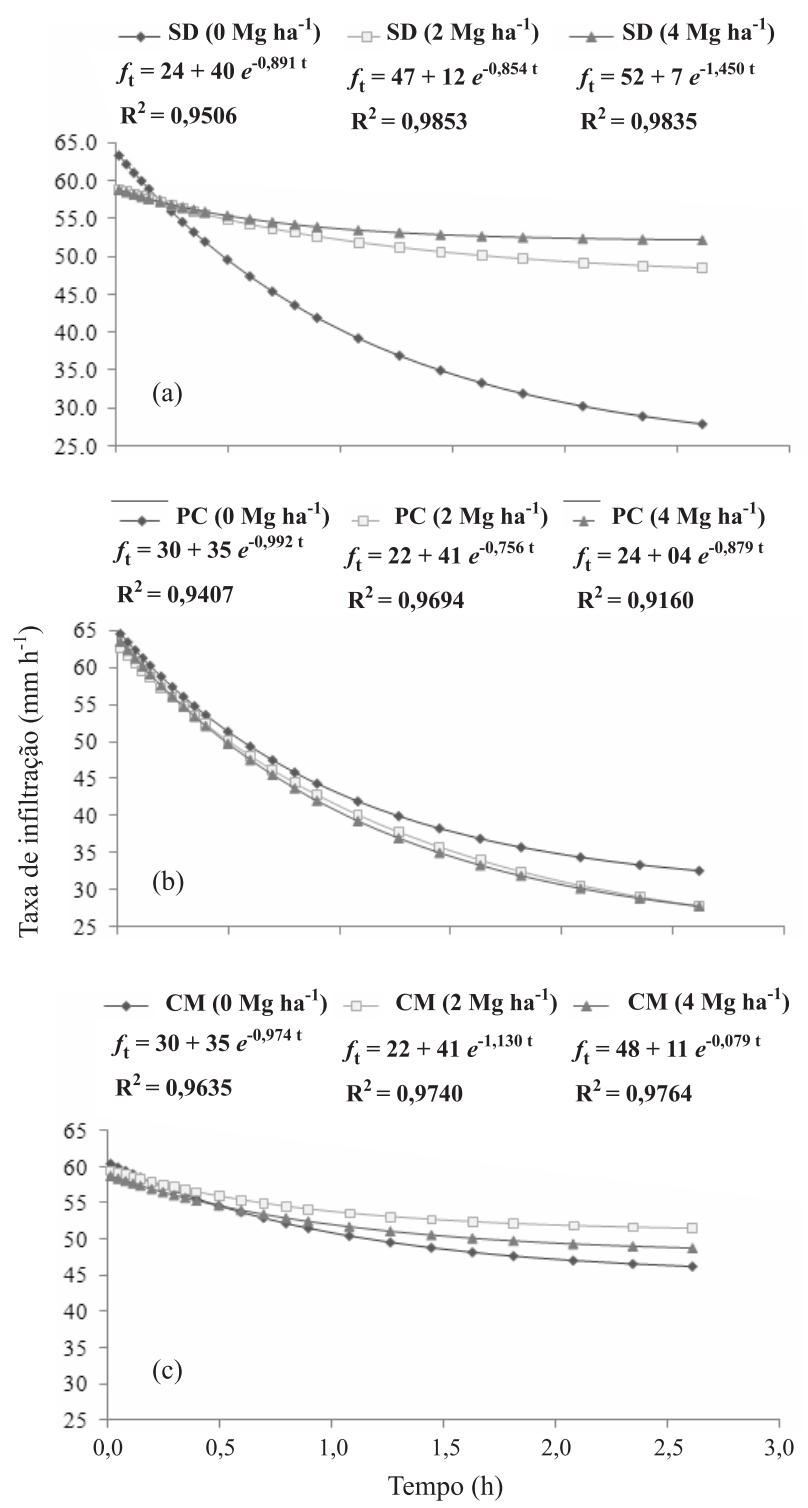

Figura 1. Taxa de infiltração estimada a partir do modelo de Horton dos tratamentos semeadura direta (SD) (a), com grade aradora (PC) (b), com escarificador (CM) (c), com níveis de resíduo vegetal de 0, 2 e $4 \mathrm{Mg} \mathrm{ha}^{-1}$.

unidade de área, foi eficaz na manutenção da infiltração de água no solo em nível elevado. Já no tratamento SD-4 o valor da TIE foi equivalente a $88 \%$ do valor inicial, não sendo, entretanto, estatisticamente superior ao obtido no tratamento SD2 (Quadro 3).

Confirma-se, dessa maneira, a importância da manutenção da cobertura do solo com quantidades elevadas de resíduo vegetal para preservar as propriedades físicas e impedir a formação de selamento superficial, que é uma das principais causas da diminuição da infiltração de água no solo. Outro aspecto a ser destacado nesse caso é que, embora na 
parcela com maior massa de resíduo vegetal não tenha ocorrido o valor da TIE superior ao observado na parcela com o valor intermediário, verificou-se maior intervalo de tempo para que o início do escoamento superficial ocorresse, diminuindo, com isso, a possibilidade de perdas por erosão hídrica.

Nos tratamentos sob preparo com grade aradora, a taxa de infiltração sofreu expressiva redução durante a aplicação das chuvas simuladas. Considerando a média dos tratamentos, os valores de TIE foram $55 \%$ menor do que a taxa de infiltração inicial (Quadro 3). Essa diminuição foi devida, basicamente, à exposição da superfície do solo ao efeito da energia cinética das gotas de chuva, que, nessas condições, pode ter promovido selamento superficial, afetando a passagem da água através da superfície do solo.

A TIE, na semeadura direta, foi maior do que no preparo com grade aradora, com exceção do tratamento SD-0. Nos tratamentos sob preparo com grade aradora, a densidade do solo e o diâmetro médio geométrico dos agregados, na camada superficial, foram ligeiramente menores do que na semeadura direta. A melhor estabilidade de agregados do solo sob semeadura direta, juntamente com a proteção da superfície do solo exercida pela cobertura do resíduo vegetal, pode ter sido a causa das maiores taxas de infiltração nesse sistema. Em estudos semelhantes, Wu et al. (1992) constataram que na semeadura direta os poros conduzem água mais eficientemente do que no preparo com grade aradora, pois, embora o solo sob semeadura direta mostre, em geral, maior densidade e menor macroporosidade, nesse tipo de manejo a condutividade hidráulica é igual ou superior à do preparo com grade aradora.

Nos tratamentos sob preparo com escarificador, observou-se que os valores da TIE foram aproximadamente $82 \%$ maiores do que os do preparo com grade aradora, sendo, entretanto, semelhantes aos da semeadura direta com cobertura vegetal morta (SD-2 e SD-4). No preparo com escarificador, os valores da TIE foram reduzidos, em média, em apenas $18 \% \mathrm{em}$ relação à taxa de infiltração inicial, permanecendo com valores relativamente altos dessa variável (Quadro 3).

As diferenças entre os valores observados no preparo com escarificador e no preparo com grade aradora devem-se, principalmente, ao fato de que, no preparo com escarificador, tanto a rugosidade superficial do solo quanto a cobertura vegetal que permaneceu sobre a superfície, no momento posterior às operações de preparo, foram maiores. Observando a condição sem resíduo vegetal nos diferentes sistemas de preparo, evidenciou-se a importância da rugosidade superficial em relação à infiltração de água no solo, pois no cultivo mínimo essas variáveis foram maiores (Quadro 2).

Nos tratamentos sob semeadura direta com resíduos vegetais, no entanto, mesmo com valores de rugosidade superficial significativamente menores do que no preparo com escarificador, a taxa de infiltração de água no solo foi alta em razão, também, do efeito da cobertura promovida pelos resíduos vegetais, o qual impediu a formação do selamento superficial. Entretanto, Cogo et al. (1984) observaram que a presença da cobertura vegetal do solo e da rugosidade superficial, atuando de maneira combinada, diminui mais eficientemente o escoamento superficial, aumentando, com isso, a infiltração da água.

\section{CONCLUSÕES}

1. Maiores perdas de solo e de água foram observadas nos tratamentos sob semeadura direta sem resíduo vegetal, enquanto nesse mesmo sistema de cultivo com a presença dos resíduos ocorreu a maior eficiência no controle da erosão hídrica.

2. Nos tratamentos do preparo com grade aradora, observaram-se maiores perdas de solo e de água do que nos do preparo com escarificador.

3. Os valores mais elevados da TIE foram encontrados nos tratamentos submetidos ao sistema de semeadura direta com a presença de resíduo vegetal e nos tratamentos sob preparo com escarificador.

\section{AGRADECIMENTOS}

À Fundação de Desenvolvimento do Ensino, Ciência e Tecnologia do Estado de Mato Grosso do Sul (FUNDECT-MS), pela concessão de bolsa e apoio financeiro ao desenvolvimento do Projeto; e ao CNPq, pela concessão da bolsa de produtividade.

\section{LITERATURA CITADA}

ALBUQUERQUE, A.W.; LOMBARDI NETO, F.; SRINIVASAN, V.S. \& SANTOS, J.R. Manejo da cobertura do solo e de práticas conservacionistas nas perdas de solo e água em Sumé, PB. R. Bras. Eng. Agr. Amb., 6:136-141, 2002.

ALVES SOBRINHO, T.; CARVALHO, D.F.; AQUINO, R.M. \& MONTEBELLER, C.A. Programa computacional para a definição de parâmetros hidráulicos utilizados na determinação da energia cinética da chuva simulada em infiltrômetro de aspersão. Eng. Rural, 12:28-35, 2001.

ALVES SOBRINHO, T.; FERREIRA, P.A. \& PRUSKI, F.F. Desenvolvimento de um infiltrômetro de aspersão portátil. R. Bras. Eng. Agr. Amb., 6:337-344, 2002.

ALVES SOBRINHO, T.; VITORINO, A.C.T.; SOUZA, L.C.F.; GONÇALVES, M.C. \& CARVALHO, D.F. Infiltração de água no solo em sistemas de plantio direto e convencional. R. Bras. Eng. Agr. Amb., 7:191-196, 2003. 
ALVES SOBRINHO, T.; MacPHERSON, H.G. \& GÓMEZ, J.A. A portable integrated rainfall and overland flow simulator. Soil Use Manag., 24:163-170, 2008.

BERTOL, I.; BEUTLER, J.F.; LEITE D. \& BATISTELA, O. Propriedades físicas de um Cambissolo Húmico afetadas pelo tipo de manejo do solo. Sci. Agric., 58:555-560, 2001.

BERTOL, I.; ZOLDAN JÚNIOR, W.A.; FABIAN, E.L.; ZAVASCHI, E.; PEGORARO, R. \& PAZ GONZÁLEZ, A. Efeito de escarificação e da erosividade de chuvas sobre algumas variáveis de valores de erosão hídrica em sistemas de manejo de um Nitossolo Háplico. R. Bras. Ci. Solo, 32:747-757, 2008 .

BERTOL, O.J.; RIZZI, N.E.; BERTOL, I. \& ROLOFF, G. Perdas de solo e água e qualidade do escoamento superficial associadas à erosão entre sulcos em área cultivada sob semeadura direta e submetida às adubações mineral e orgânica. R. Bras. Ci. Solo, 31:781-792, 2007.

BEUTLER, J.F.; BERTOL, I.; VEIGA, M. \& WILDNER, L.P. Perdas de solo e água num Latossolo Vermelho aluminoférrico submetido a diferentes sistemas de preparo e cultivo sob chuva natural. R. Bras. Ci. Solo, 27:509-517, 2003.

CARVALHO, D.F.; CRUZ, E.S.; PINTO, M.F.; SILVA, L.D.B. \& GUERRA, J.G.M. Características da chuva e perdas por erosão sob diferentes práticas de manejo do solo. R. Bras. Eng. Agr. Amb., 13:3-9, 2009.

CASSOL, E.A. \& LIMA, V.L. Erosão em entressulcos sob diferentes tipos de preparo e manejo do solo. Pesq. Agropec. Bras., 38:117-124, 2003.

COGO, N.P. Effect of residue cover, tillage induced-roughness, and slope length on erosion and related parameters. West Lafayette, Purdue University, 1981. 346p. (Tese de Doutorado)

COGO, N.P.; MOLDENHAUER, W.C. \& FOSTER, G.R. Soil loss reductions from conservation tillage practices. Soil Sci. Soc. Am. J., 48:368-373, 1984.

COGO, N.P.; LEVIEN, R. \& SCHWARZ, R.A. Perdas de solo e de água por erosão hídrica influenciadas por métodos de preparo, classes de declives e níveis de fertilidade do solo. R. Bras. Ci. Solo, 27:743-753, 2003.

EMPRESA BRASILEIRA DE PESQUISA AGROPECUÁRIA EMBRAPA. Centro Nacional de Pesquisa de Solos. Manual de métodos de análise de solo. 2.ed. Rio de Janeiro, Embrapa, 1997. 212p.
HORTON, R. The role of infiltration in the hydrological cycle. Trans. Am. Geophys. Union, 14:446-460, 1933.

JOHANSEN, I. Software Graph 4.3, versão 4.3. 2009. Disponível em <http://www.padowan.dk/graph/>. Acesso em mar. de 2010.

KEMPER, W.D. \& ROSENAU, R.C. Aggregate stability and size distribution. In: KLUTE, A. Methods of soil analysis: Physical and mineralogical methods. 2.ed. Madison, American Society of Agronomy, Soil Science Society of America, 1986. Part 1. p.425-442.

MELLO, E.L.; BERTOL, I.; ZAPAROLLI, V. \& CARRAFA, M.R. Perdas de solo e água em diferentes sistemas de manejo de um nitossolo háplico submetido à chuva simulada. $R$. Bras. Ci. Solo, 27:901-909, 2003.

PANACHUKI, E.; ALVES SOBRINHO, T.; VITORINO, A.C.T.; CARVALHO, D.F \& URCHEI, M.A. Avaliação da infiltração de água no solo, em sistema de integração agricultura-pecuária, com uso de infiltrômetro de aspersão portátil. Acta Sci. Agron., 28:129-137, 2006.

PANACHUKI, E. Rugosidade superficial do solo e índices relacionados, sob diferentes sistemas de manejo. Dourados, Universidade Federal da Grande Dourados, 2008. 143p. (Tese de Doutorado)

TISDALL, J.M. \& OADES, J.M. Organic matter and water stable aggregates in soils. J. Soil Sci., 33:141-163, 1982.

SILVA, L.C. \& KATO, E. Avaliação de modelos para a previsão da infiltração de água em solos sob cerrado. Pesq. Agropec. Bras., 33:1149-1158, 1998.

VOLK, L.B.S.; COGO, N.P. \& STRECK, E.V. Erosão hídrica influenciada por condições físicas de superfície e subsuperfície do solo resultantes do seu manejo, na ausência de cobertura vegetal. R. Bras. Ci. Solo, 28:763774,2004

WU, L.; SWAN, J.B.; PAULSON, W.H. \& RANDALL, G.W. Tillage effects on measured soil hydraulic properties. Soil Tillage Res., 25:17-33, 1992.

ZOLDAN JÚNIOR, W.A.; BERTOL, I.; PEGORARO, R.; FABIAN, E.L.; ZAVASCHI, E. \& VIDAL VÁZQUEZ, E. Rugosidade superficial do solo formada por escarificação e influenciada pela erosividade da chuva. R. Bras. Ci. Solo, 32:353-362, 2008. 
